\title{
Coexistence of ankylosing spondylitis and discoid lupus: A case report
}

\author{
Ayse Unal Enginar, (1) Hakan Nur, (1) Cahit Kacar \\ Department of Physical Medicine and Rehabilitation, Akdeniz University Faculty of Medicine, Antalya, Turkey
}

\begin{abstract}
Coexistence of ankylosing spondylitis with connective tissue diseases is very rare. Here, in this study, we describe a coexistence of ankylosing spondylitis and discoid lupus erythematosus in a 35-year-old man. He presented with a 5-year history of low back pain and concurrent development of a discoid rash. Inflammatory low back pain, HLA-B27 positivity and bilateral active sacroiliitis confirmed the diagnosis of ankylosing spondylitis. Discoid lupus erythematosus was diagnosed based on a skin biopsy. There are reports of discoid lupus associated with medications, particularly with tumour necrosis factor-alpha (TNF- $\alpha$ ) blocking drugs. However, the patient presented here had coexistence of ankylosing spondylitis and discoid lupus before starting such treatments.
\end{abstract}

Keywords: Ankylosing spondylitis; discoid lupus; systemic lupus erythematosus.

Cite this article as: Unal Enginar A, Nur H, Kacar C. Coexistence of ankylosing spondylitis and discoid lupus: a case Report. North Clin Istanb 2019;6(4):412-414.

A nkylosing spondylitis (AS) is a chronic and systemic rheumatic disease primarily affecting the axial skeleton [1]. Systemic lupus erythematosus (SLE) is a complex rheumatic disease characterized by the involvement of multiple organs with various symptoms. Cutaneous involvement is seen in $72-85 \%$ of the patients with SLE, which could be observed as an initial finding in $23-28 \%$ of the patients [2]. Chronic cutaneous lupus erythematosus (CCLE) primarily affects the face with a presentation of erythema, hyperkeratotic, discoid appearance plaque and heals with scars. Discoid lupus erythematosus (DLE) is the most commonly seen localised variant of CCLE.

AS and SLE, which have different etiopathogenesis and different clinical and genetic characteristics, are rarely seen together. There is a limited number of reports about the coexistence of these two diseases [3-12]. Here, in this study, we describe a male patient with the coexistence of AS and DLE.

\section{CASE REPORT}

A 35-year old male patient was admitted to the outpatient clinic with low back pain who had these complaints for five years and had been diagnosed as ankylosing spondylitis two years ago. He had a history of non-steroid anti-inflammatory drugs usage that had been inadequate for the relief of the symptoms. The patient also had an erythematous plaque on the bridge of the nose for five years with a history of an increase in skin lesions in the previous year (Fig. 1). There were no peripheral arthritis, uveitis, psoriasis or inflammatory intestinal disease and also no clinical findings of systemic involvement and the family history of rheumatic diseases. In physical examination increased thoracic kyphosis and reduced cervical and lumbar range of motion were detected. Lumbar Schober was $1.5 \mathrm{~cm}$, finger base distance was $25 \mathrm{~cm}$, and jaw manubrium distance was 0 . Sacroiliac compression tests were bilaterally pos-

Received: November 02, 2018 Accepted: December 26, 2018 Online: November 22, 2019

Correspondence: Dr. Ayse UNAL ENGINAR. Akdeniz Universitesi Tip Fakultesi, Fiziksel Tip ve Rehabilitasyon Anabilim Dali, Antalya, Turkey. Tel: +90 5327239988 e-mail: ftrdrayseenginar@gmail.com

(c) Copyright 2019 by Istanbul Provincial Directorate of Health - Available online at www.northclinist.com 
itive. BASDAI score was 6. Anti-nuclear antibody and anti-dsDNA were negative. Erythrocyte sedimentation rate (ESR) was $40 \mathrm{~mm} / \mathrm{hr}$ and C-reactive protein (CRP) was $2.5 \mathrm{mg} / \mathrm{dl}$ (CRP normal range $0-0.5 \mathrm{mg} / \mathrm{dl}$ ). Complement tests, full blood count, liver and kidney functions, serum protein and creatinine phosphokinase levels, thyroid function tests, urine analysis and urine protein/creatinine ratio were within a normal range. Hepatitis B and C viruses, HIV and Brucella serology were negative. HLA-B27 was positive. The pulmonary radiograph was normal. On the pelvis radiograph grade 3-4 bilateral sacroiliitis were seen (Fig. 2).

A skin biopsy was performed and mononuclear inflammatory cell infiltration around the hair follicles on the dermis and increased mucin in the dermal papilla were seen (Fig. 3). After a diagnosis of ankylosing spondylitis and discoid lupus, $40 \mathrm{mg} / 2$ weeks subcutaneously adalimumab, $400 \mathrm{mg} /$ day hydroxychloroquine and topical tacrolimus were started. Using a high factor protective sun cream was recommended. In the followup, the clinical symptoms of AS were significantly improved.

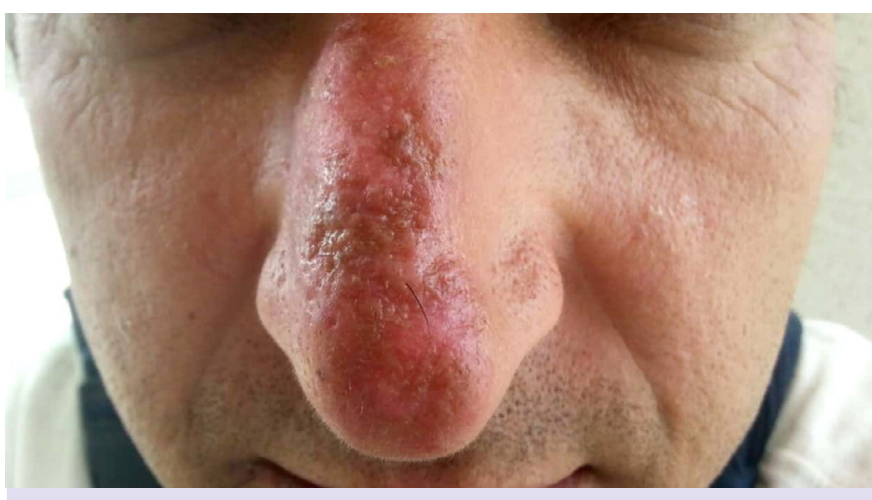

FIGURE 1. Discoid lesions.

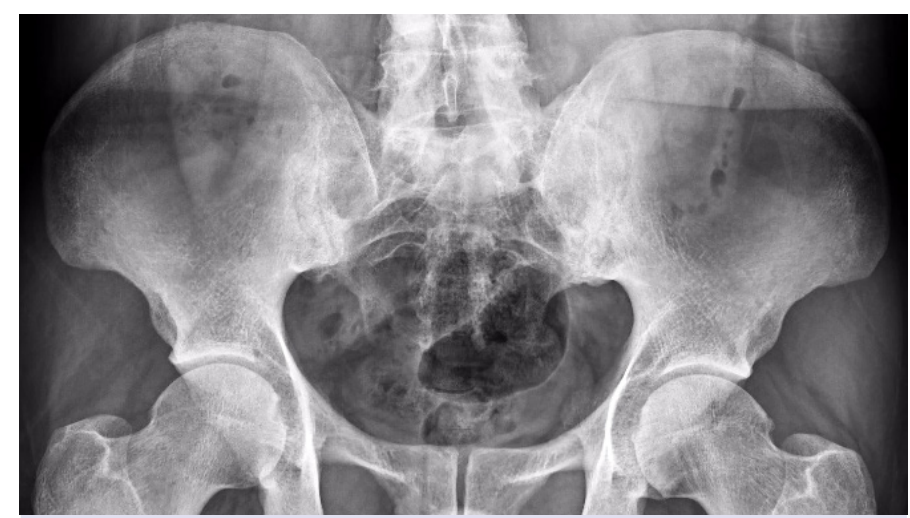

FIGURE2. Bilateral sacroiliitis.

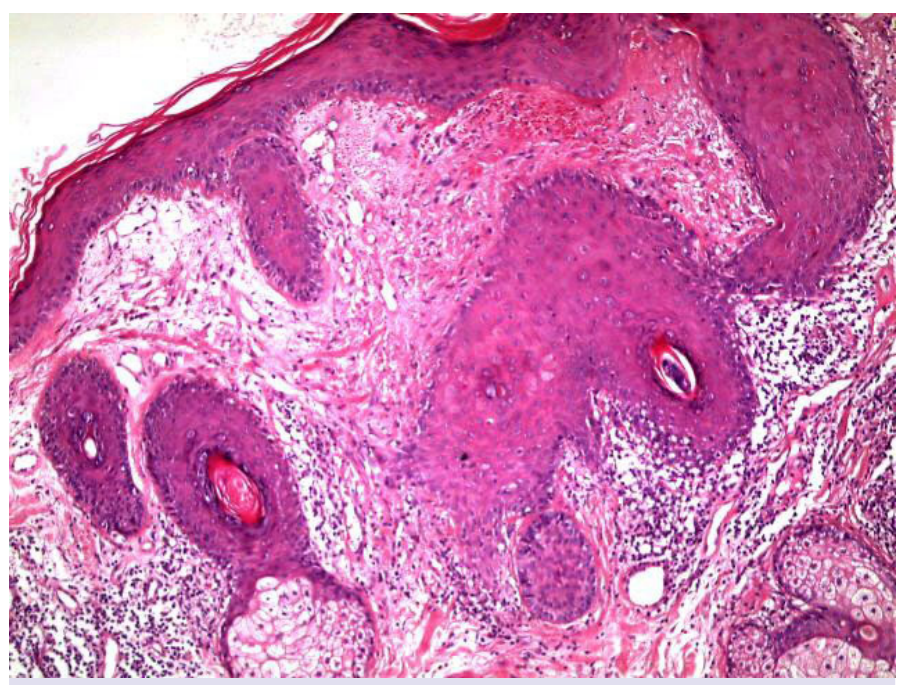

FIGURE 3. Bilateral sacroiliitis.

\section{DISCUSSION}

Coexistence of AS and SLE is very rare, with a limited number of cases reported in the literature [3-12]. AS is frequently seen in male patients and SLE is frequently seen in female patients. Coexistence of these two diseases are predominantly reported in female patients and in the majority of the cases complaints related to AS and diagnosis of AS was before the diagnosis of SLE [3-8, 10, $12]$. Our patient was a male and his complaints related to AS and DLE started at the same time. Inflammatory low back pain, HLA-B27 positivity and bilateral active sacroiliitis confirmed the diagnosis of AS based on the modified New York criteria. DLE was diagnosed according the results of a skin biopsy. In the literature, there are reports with various combinations of AS with findings of SLE such as hematological and renal involvement, malar rash, ANA, anti-dsDNA, hypocomplementemia, thrombocytopenia, and leukopenia [3-12]. In contrast, in our patient, there was only DLE and no systemic involvement was detected.

Nashel et al. [3] reported a black male patient with HLA-B27 antigen combination with DR2 and DR3 antigens affected by both AS and SLE. Combination of genetically determined markers seems to have caused an increased risk for the development of both disorders. Although HLA-B27 was positive in our patient, we could not look for DR2 or DR3 antigens. Patients with AS often use anti-TNF drugs. In patients with AS, rheumatoid arthritis (RA), and inflammatory intestinal disease who were treated with anti-TNF drugs rarely discoid lupus was reported. Stratigos et al. [13] reported 
a RA patient who developed discoid lupus during infliximab therapy and the skin lesions of the patient recovered with antimalarial treatment after terminating infliximab. Unlike these reports, the findings of DLE emerged before the anti-TNF treatment in our patient. The findings were not related to the drugs and the patient had no systemic symptoms of lupus.

SLE may develop in $5 \%-10 \%$ of the DLE patients [14]. If DLE lesions are in a disseminated form with trunk involvement, there is an increased risk of systemic involvement [2]. Also, there is a risk of the development of squamous cell carcinoma in discoid lupus lesions [15]. Great care should be taken in this respect. Skin biopsy was reported as DLE in our patient, and no findings of malignancy were determined. Symptoms of SLE have not been detected during the follow-up of the patient.

In conclusion, here, we reported a male patient with coexistence of AS and DLE. It should be kept in mind that although they have different etiopathogenesis, genetic and clinical factors, coexistence of these diseases could be very rarely seen.

Informed Consent: Written informed consent was obtained from the patient for the publication of the case report and the accompanying images.

Conflict of Interest: No conflict of interest was declared by the authors.

Financial Disclosure: The authors declared that this study has received no financial support.

Authorship Contributions: Concept - AUE, HN, CK; Design AUE, HN, Supervision - AUE, HN, CK; Materials - AUE, HN, CK; Data collection and processing - $\mathrm{AUE}, \mathrm{HN}, \mathrm{CK}$; Analysis and interpretation - AUE, HN, CK; Writing - AUE; Critical review - AUE, HN, CK.

\section{REFERENCES}

1. Rudwaleit M, Landewé R, van der Heijde D, Listing J, Brandt J, Braun J,et al. The development of Assessment of SpondyloArthritis international Society classification criteria for axial spondyloarthritis (part I): classification of paper patients by expert opinion including uncertainty appraisal. Ann Rheum Dis 2009;68:770-6. [CrossRef]

2. Kuhn A, Landmann A. The classification and diagnosis of cutaneous lupus erythematosus. J Autoimmun 2014;48-49:14-9. [CrossRef]

3. Nashel DJ, Leonard A, Mann DL, Guccion JG, Katz AL, Sliwinski AJ. Ankylosing spondylitis and systemic lupus erythematosus: a rare HLA combination. Arch Intern Med 1982;142:1227-8. [CrossRef]

4. Olivieri I, Gemignani G, Balagi M, Pasquariello A, Gremignai G, Pasero G. Concomitant systemic lupus erythematosus and ankylosing spondylitis. Ann Rheum Dis 1990;49:323-4. [CrossRef]

5. Korkmaz C. Delayed diagnosis of porphyria based on manifestations of systemic lupus erythematosus and ankylosing spondylitis. J Nephrol 2006;19:535-9.

6. Chandrasekhara PK, Jayachandran NV, Thomas J, Narsimulu G. Systemic lupus erythematosus and dermatomyositis with symptomatic bilateral sacroiliitis: an unusual and interesting association. Mod Rheumatol 2009;19:84-6. [CrossRef]

7. Singh S, Sonkar GK, Singh U. Coexistence of ankylosing spondylitis and systemic lupus erythematosus. J Chin Med Assoc 2010;73:260-1.

8. Jiang L, Dai X, Liu J, Ma L, Yu F. Hypoparathyroidism in a patient with systemic lupus erythematosus coexisted with ankylosing spondylitis: a case report and review of literature. Joint Bone Spine 2010;77:608-10.

9. Mrabet D, Rekik S, Sahli H, Trojet S, Cheour I, Eleuch M, et al. Ankylosing spondylitis in female systemic lupus erythematosus: a rare combination. Lupus 2011;20:777-8. [CrossRef]

10. Kook MH, Yoo HG, Hong MJ, Yoo WH. Coexisting systemic lupus erythematosus and ankylosing spondylitis: a case report and review of the literature. Lupus 2012;21:348-9. [CrossRef]

11. Tarhan F, Argin M, Can G, Özmen M, Keser G. Coexistence of systemic lupus erythematosus and ankylosing spondylitis: another case report and review of the literature. Eur J Rheumatol 2014;1:39-43.

12. Akbaryan M, Soltani Z. Overlap of Ankylosing Spondylitis and Systemic Lupus Erythematosus: A case report. Int J Med Res Health Sci 2016;5:100-3.

13. Stratigos AJ, Antoniou C, Stamathioudaki S, Avgerinou G, Tsega A, Katsambas AD. Discoid lupus erythematosus-like eruption induced by infliximab. Clin Exp Dermatol 2004;29:150-3. [CrossRef]

14. Santiago-Casas Y, Vilá LM, McGwin G Jr, Cantor RS, Petri M, Ramsey-Goldman R, et al. Association of discoid lupus erythematosus with clinical manifestations and damage accrual in a multiethnic lupus cohort. Arthritis Care Res (Hoboken) 2012;64:704-12. [CrossRef]

15. Costner MI, Sontheimer RD. Chapter 155: Lupus erythematosus. In: Freedberg IM, Eisen AZ, Wolff K, Austen KF, Goldsmith LA, Katz S, editors. Fitzpatrick's Dermatology in General Medicine. 6th ed. McGraw-Hill Professional; 2003. p. 1677-93. 